\title{
Sistema Métrico Decimal no Pará
}

\author{
Decimal Metric System in Pará, Brazil
}

Patrícia de Campos CORRÊA ${ }^{1}$

\section{Resumo}

O sistema métrico decimal utilizado cotidianamente, na contemporaneidade, dista dos problemas ocasionados durante sua criação e implantação tanto na França como no Brasil. O presente artigo pretende mostrar como este conhecimento foi difundido no Pará no contexto da Belle Époque. No Brasil, o sistema foi implantado legalmente por D. Pedro II ao promulgar a Lei Imperial n. 1.157 de 1862. Deste feito, o sistema métrico francês se tornou o padrão de medidas e de ensino obrigatório nas escolas, além de ter sido estipulado um prazo de dez anos para o abandono definitivo de outras formas de realizar medidas. Esta decisão fazia parte do processo modernizador civilizatório impulsionado pela racionalidade científica, pela industrialização pela qual os países passavam, pelo fortalecimento do mercado consumidor. No Pará, o sistema métrico foi introduzido nos currículos e nos programas de ensino requerendo aulas práticas com uso de equipamentos de medição por método intuitivo em escolas de todos os níveis de ensino: primário, secundário e cursos profissionalizantes em atendimento as necessidades da sociedade à época da exportação da borracha.

Palavras-chave: sistema métrico; escolas paraenses; Belle Époque

\section{Abstract}

The metric systems used daily, in contemporary times do not remember the problems caused during its creation and implementation in France as well as Brazil. This article aims to show how this knowledge was widespread in Pará in the Belle Époque context. The system was implemented legally in Brazil by D. Pedro II who promulgated the Imperial Law n. 1 $157 / 1862$. Thus the system become official as standard measures and compulsory education in schools also determined ten years for the permanent abandonment other kind of measures. It was part of civilizing process of modernization as a consequence of scientific rationality, the countries industrialization and the market. The metric system was introduced in Pará by curricular and teaching programs required practical classes of measure, intuitive method in schools of all education levels: primary, secondary and vocational courses according the society needs during latex

Keywords: metric system; Pará schools; Belle Époque

\footnotetext{
${ }^{1}$ Secretaria de Estado de Educação do Pará (SEDUC/PA)
} 


\section{Sistema Métrico Decimal - modernidade francesa}

Na contemporaneidade o Sistema Métrico Decimal, pensado e elaborado na França à época do Iluminismo, se apresenta como um conhecimento vulgarizado e incorporado por pessoas em atividades corriqueiras de rotina, que utilizam esse sistema permeando a existência de cada sujeito de forma automática, sem pensar ou refletir sobre o mesmo. Uma pessoa nos dias de hoje pode ter uma balança no banheiro para aferir sua massa corpórea ou ainda abrir a geladeira e armazenar com fins de refrigerar um litro de guaraná. Tais atividades diárias, tão distantes dos percalços ocorridos para a criação do Sistema de Medidas, e pelos quais os governos de vários países passaram ao objetivarem executar estratégias para a implantação do referido Sistema com fins de facilitar o comércio (importação/exportação) após acordos internacionais estabelecidos a partir da Convenção do Metro realizada em 1875, da qual embora estivesse presente, o Brasil não se tornou signatário naquele momento, mas iniciou medidas com esse fim, inclusive legislando a respeito (ROZEMBERG, 2008).

Ao observar o mundo contemporâneo por outro ângulo, diferentemente do acima mencionado, e percebe-se que o sujeito pode adquirir novas tecnologias com medidas antropométricas: um televisor, ou ainda um monitor de computador de quarenta polegadas, viajar em aeronaves a vinte e cinco mil pés de altitude. Pode-se passear em um cruzeiro marítimo em milhas náuticas viajando a velocidade de nó por hora, há quem adquira maço de cigarro, medidas não pertencentes ao Sistema Internacional, mas que continuam a ser utilizadas, ou seja, coexistem.

Com um olhar ainda mais atento percebe-se que o sujeito pode comprar pão por unidade em padarias de bairro, bananas por dúzia, cinco laranjas por três Reais, como brada o feirante no afã de seduzir seus fregueses. Na Amazônia, conforme pesquisa realizada por Trindade (2009), que mostra uma variedade de medidas, fora do padrão do Sistema Internacional, das compras em feiras livres - ato corriqueiro: maço de cheiro verde ou coentro, cambada de peixes, rasa de açaí, paneiro de ananás, cuia de camarão, sendo estes alguns dos representantes das unidades de medidas caboclas amazônicas peculiares da região, as quais diferem das firmadas pelo acordo modernista iluminista. Ressaltando-se que este fenômeno se repete em todo o Estado do Pará.

Trindade (2009) aponta que na Feira do Ver-o-Peso, situada na cidade de Belém, capital do estado do Pará, a qual ocupa uma área de trinta e cinco mil metros quadrados, onde trabalham cerca de mil e quinhentas pessoas distribuídas em mil quatrocentas e vinte barracas, atende em média, mil e duzentos visitantes diariamente (PARATUR, 2014) atraídos pela enorme variedade de produtos, com funcionamento de vinte e quatro horas por dia. Esses feirantes costumam imprimir novos usos atribuídos aos equipamentos de medidas criados pelos cientistas modernos tais como: litro de castanha-do-pará, litro de farinha de mandioca, litro de tapioca, litro de camarão. Tal fenômeno se repete pelas demais quarenta e duas feiras, bem como pelos dezoito mercados que funcionam legalmente em Belém. 0 litro padrão pressupõe uma unidade de medida para fluidos, entretanto, curiosamente tem sido utilizado para medir sólidos, e estranhamente os compradores não questionam esses novos usos dos equipamentos de medidas e tampouco se sentem lesados ao aceitar pagar pelos produtos vendidos desse modo, embora (se pressupõe) eles tenham estudado nas escolas o Sistema Internacional de Unidades, uma vez que é assunto obrigatório no currículo escolar brasileiro desde a época do Brasil Império. 
A cidade de Belém foi fundada pelo capitão mor Francisco Caldera Castelo Branco, em 12 de janeiro de 1616, (De 1616 a 1640 Portugal fazia parte da União Ibérica, cujo governante era o Rei espanhol Filipe II que com a crise de sucessão foi coroado em Portugal como Filipe I) como parte do projeto político português de expansão econômica e de conquista territorial no além-mar, expedição esta que edificou um forte objetivando combater corsários ingleses, holandeses, franceses na Amazônia, interessados em ocupar as terras e explorar minério - ouro e drogas do sertão. Ao longo desse tempo existiram outras formas de medir que não foram abandonadas por completo, embora na atualidade tenha se tornado um centro urbano na Amazônia, a capital do estado do Pará.

$\mathrm{Na}$ feira do Ver-o-Peso, alguns feirantes embora possuam balanças digitais, permanecem oferecendo produtos sólidos a litro, como a castanha-do-pará, para ilustrar. Segundo o próprio feirante, ele ganha mais se vender o produto desta forma, e a balança estaria exposta para ser mostrada aos fiscais da prefeitura, caso o questionem. Além disso, as balanças devem conter o selo do Instituto Nacional de Metrologia, Qualidade e Tecnologia (INMETRO), que também é responsável por fiscalizar a aferição correta desse tipo de equipamento metrológico e aplicar multas aos infratores. Contudo os consumidores não tem a preocupação de observar se os equipamentos de medidas contêm o selo do INMETRO e tem sido recorrente nos noticiários fraudes em balanças. No Brasil é ilegal comercializar produtos em desacordo com o Sistema Internacional, muito embora diariamente se vivencie contraditoriamente e se experiencie outras formas de medições distantes do sistema legalmente instituído.

Esses múltiplos olhares para o Sistema de Medidas nos permite pensar nas relações que se estabeleceram historicamente entre ciência, cultura, tradição, modernidade, sociedade, tecnologia, educação escolar e não escolar, nas contradições, nas imposições, no poder, no discurso predominante, nas resistências, nas negociações, nas condições, nos sujeitos, nos contextos, nos acordos, no local de fala, na economia, na política enfim na teia que se construiu e se constrói com esta temática e por isso mesmo, por parecer tão complexa, tão imbricada, tão recheada e permeada de elementos, de fatores foi escolhida como estudo tendo como lócus a Amazônia.

Neste sentido, este artigo pretende mostrar como o Sistema Métrico Decimal, cultura científica moderna, foi difundido no Pará por meio das escolas, em atendimento aos preceitos legais nacionais. Identificar os currículos e programas de ensino das escolas na introdução do Sistema Métrico Decimal, com o estudo sobre o contexto da época de transição do Século XIX para o Século XX, com a emergência das ciências modernas. Identificar o processo de como o conhecimento do Sistema Métrico Decimal foi se consolidando nos vários níveis de ensino.

\section{O Sistema Métrico Francês}

A França, na época da massificação do pensamento iluminista, utilizava algo em torno de vinte e cinco unidades diferentes de medidas ocasionando fraudes que dificultavam a cobrança de impostos. Com o intuito de ordenar a cobrança racional, organizar as relações entre consumidores, produtos e vendedores objetivando minimizar desconfianças, enganos, discordâncias. Essa atmosfera se torna aparentemente favorável para que se pense em criar um sistema único de medidas, que fosse simples e de rápida apropriação pela população, porque assim se garantiria a igualdade aos homens e libertaria o país da corrupção e da cobrança abusiva de taxas instituídas pelo Antigo Regime (ALDER, 2003). Neste sentido, o 
Sistema é pensado para uso interno e externo. Mas para que se tornasse de uso externo se fazia necessário à aceitação desse Sistema por outros países. O ideário iluminista era de trazer a razão para o Sistema de medidas eliminando medidas imprecisas como as antropométricas e esgotar a diversidade de padrões regionais com os quais o ganho de uns era a perda de outros, sem igualdade, sem equilíbrio nas transações comerciais.

O Sistema Métrico Decimal, encomendado à Academia de Ciências de Paris durante o reinado de Luis XVI, só foi apresentado à Assembleia Nacional em maio de 1793, após o rei ter sido julgado, condenado por traição e por fim guilhotinado, e a Academia de Ciências (fundada em 1666 por Luis XIV em atendimento ao sugerido pelo Ministro Jean-Batiste Colbert) foi fechada neste mesmo ano pelos revolucionários. Assim, a Assembleia Nacional autorizou a confecção dos padrões de comprimento e de massa, para uso provisório.

A Academia de Ciências de Paris foi restaurada em 1795 como parte do Instituto Nacional, pois os acadêmicos justificaram que a criação do Sistema traria visibilidade e respeitabilidade para a recém-criada República Francesa que em função da revolução não era bem vista pelos países onde havia reinados. Assim, a comissão de cientistas pode continuar seus trabalhos com o Sistema Métrico Decimal. O trabalho de medição para a criação da unidade de medida linear foi concluída somente em 1799.

Anteriormente a existência do Sistema Métrico Decimal utilizava-se na França uma variedade de unidades de medidas o que complicava o comércio interno e externo, prejudicando a arrecadação de impostos e dificultando a administração governamental. Somando-se a isso, os iluministas idealizavam encontrar um padrão de medida elaborado com o rigor científico necessário de forma que fosse sistemático, racional, prático, preciso, simples e fácil de ser usado no que se referem aos cálculos, as conversões e as relações de precificação. Para eliminar as controvérsias em relação às medidas ocasionadas pela infinidade de padrões regionais, o novo padrão seria criado com base na natureza, com fins de se tornar uma verdade imutável, e outro ponto importante é que caso o padrão sofresse danos pela ação do tempo, este poderia ser reconstituído em sua materialização, e por isso mesmo poderia se tornar um padrão universal a ser adotado por todos os povos.

Os estudos para que se encontrasse o padrão de unidade de medida linear ideal foram iniciados na vigência do reinado de Luis XVI, mas com o advento da Revolução Francesa foram interrompidos, sendo retomados mais tarde. Após algumas experiências a Comissão de cientistas decidiu por escolher como referência para a criação do padrão uma medida baseada na natureza imutável, isto é, a medida de um meridiano terrestre. Considere que a Terra existe e, tendo assim suas dimensões, estas podem ser medidas e se tornarem referência para a construção de um padrão baseado na natureza. E como a natureza não pertence a ninguém, o padrão nasceria trazendo desde a sua concepção a possibilidade de ser aceito por todos os países, por todas as pessoas.

A primeira ideia seria utilizar a relação decimal tendo por base a medida do comprimento do pêndulo que oscila a latitude $45^{\circ}$ em um minuto, mas como a longitude do pêndulo não era constante em todo o planeta por causa do ligeiro achatamento da Terra prevaleceu uma segunda ideia, a de utilizar por base à medida de um meridiano terrestre, este sim invariável, sendo aceita pela Assembleia Nacional. Para viabilizar os trabalhos de criação do metro foram realizadas duas expedições para medir o meridiano $45^{\circ}$ iniciadas em 1792 e finalizadas somente em 1799. Uma expedição seguiu pelo Norte (Paris - Dunquerque) com Jean-Joseph Delambre e a outra pelo sul (Paris Barcelona/Espanha) com Pierre-François-André Méchain, com o objetivo de calcular a medida do pólo norte ao equador e deste feito, calcular a medida exata do mundo. Ambas 
as expedições encontraram empecilhos variados para alcançar seus objetivos em função da Revolução Francesa e de problemas na Espanha.

Os cientistas da Royal Society of London acusaram os franceses de medir o seu próprio meridiano para tornar um padrão universal, o que conforme alegaram seria uma medida arbitrária ao se considerar a medida de um geoide imaginário. Se o meridiano não existe, basear um Sistema Métrico em medidas antropométricas palpáveis, que se encontravam ao alcance de qualquer pessoa era mais legítimo, mais racional, mais inteligível a usar algo que existiria no mundo das ideias como um geóide Francês imaginário. Considere que a França desde a Idade Média (Guerra dos 100 anos, com duração de 116 anos; Guerra dos 7 anos e a interferência na Independência dos Estados Unidos em 1783 - com intenção de prejudicar o comércio inglês) se relacionava problematicamente com a Inglaterra. Esses episódios marcaram negativamente o país e sua relação mútua, que pode ter influenciado a decisão dos ingleses em não avalizar o novo sistema pensado por franceses. Ocorre que as medidas antropométricas que estavam em uso além de variarem de tamanho, as unidades não derivam umas das outras como pé e braça, para ilustrar.

\section{Sistema métrico - da França para o Brasil}

No Brasil o crescimento industrial fez crescer a necessidade de proteger o consumidor e o mercador com a adoção do sistema de medidas moderno em conformidade com o modo laico de pensar conforme o cientificismo despontado à época. Neste sentido, no ano de 1862, D. Pedro II influenciado por pessoas antenadas com a racionalidade científica, promulgou a Lei Imperial n. 1.157, com a qual instituiu o Sistema Internacional de Pesos e Medidas e estipulou um prazo de dez anos para o abandono definitivo de outras unidades de medidas que eram utilizadas no reino. Após esse período o imperador do Brasil determinou a importação dos padrões de medidas e distribuição em todo reino, além de tornar obrigatório seu ensino nas escolas.

Para consolidação da implantação do novo sistema de medidas o Brasil fez parte da Conferencia Diplomática do Metro realizada em 1875, na França, tendo sido representado pelo Visconde de Itajubá e pelo General Morin, reunidos com representantes de vinte países para a assinatura da Convenção Internacional do Metro e criação do Bureau Internacional de Pesos e Medidas com fins de assegurar a unificação mundial das medidas físicas.

O sistema métrico decimal não foi aceito pacificamente no Brasil, mas desencadeou resistências, até mesmo violentas, como a Revolta do Quebra-Quilos iniciada na Paraíba em 14 de novembro de 1874 onde a população destruiu os equipamentos de medidas, incendiou o cartório, matou dois funcionários do Estado, sendo um o chefe dos pesos, soltou os presos que estavam na cadeia e, se estendeu por outras 80 localidades do Rio Grande do Norte, de Alagoas e Pernambuco com forte repressão pelo Governo Imperial culminando com a prisão dos líderes (SECRETO, 2012).

Esta Revolta mostra como foi a receptividade destes equipamentos de medidas pela população nordestina que entre outros fatores, como o desconhecimento de manipulação e relação com precificação se rebelou contra as novas medidas enfatizando a resistência do povo contrário as imposições governamentais relativas à cobrança de impostos (imposto do chão), corrupção, desmandos, prisão de religiosos (bispos do Pará e de Olinda) por excomungar maçons, o recrutamento de jovens para serviço militar, e a escravidão (LIMA, 2009; LIMA, 2001; SECRETO, 2011). 
Para instituir o sistema métrico francês no Brasil entre os meados do século XIX e início do Século XX, este se tornou assunto obrigatório nas escolas e isso pode ser visto nos livros que circularam à época, a metodologia indicada nos programas escolares e os currículos escolares. Zuin (2007) identifica os compêndios, manuais e livros de Arithmetica que usavam o método intuitivo e mostra a cultura escolar expressa nos livros escolares.

\section{O sistema métrico no Pará}

No Pará, A presença do Sistema Internacional pode ser observada em 1871 no Currículo da Escola Normal, quando ela foi criada em 13 de abril, em conformidade com a Lei No. 669/1871, para formar professores para atuar na instrução primária da Província objetivando alcançar melhores resultados no desempenho dos alunos do ensino primário. Na matriz curricular desta Escola constava a cadeira "Aritmética. Sistema Métrico. Elementos de Geometria" (CRUZ, 1973, p 359 - 360).

A introdução desta cadeira faz parte do processo de difusão de conhecimentos que se originou na França e foi irradiado para outros lugares do mundo inclusive para a Amazônia. Entretanto, a transferência de conhecimentos não ocorre em espaços social e cultural vazio, pois os materiais preexistentes alteram os conhecimentos, cuja síntese é resultado de um processo de "negociações" ocorridas no encontro entre as duas culturas (ARBOLEDA, 1987).

Na Escola Normal, criada na década de 70 na Província do Gram Pará (BARROS, 2010) com a finalidade de formar professores de ambos os sexos, existia a cadeira Sistema Métrico tal a relevância desse conhecimento em ser ensinado para ser apropriado pelas crianças, ser em formação, com o propósito de mudança comportamental, em função dos acordos internacionais firmados pelo Governo Imperial e pelo contexto da industrialização e da importação de um modelo civilizatório.

Além disso, constava no Currículo da Escola Primária Inferior da Província do Gran Pará, conforme os preceitos estabelecidos na Lei n. 664, de 31 de outubro de 1870, a cadeira Noções práticas do Sistema Métrico de pesos e medidas. Assim, ao ser criada a Escola Normal em 1871, foi inserida a cadeira Sistema Métrico para formar professores que ao adquirir esses conhecimentos pudessem então ensiná-los na Instrução Primária. E, ao ter sido recriada em 1874, esta cadeira se manteve.

Vinte anos após a criação da Escola Normal, isto é, em 1891, foi publicado o Regulamento Geral da Instrução Pública e Especial do Ensino Primário do Estado do Pará que entre outros assuntos, esse documento destaca os conteúdos a serem ministrados nas escolas elementares: $1^{\circ}$ - $O$ ensino concreto das formas, cores, números, dimensões, tempo, sons, qualidades dos objetos, medidas, seu uso e aplicação; $2^{\circ}$ - Geometria prática e noções sobre a medição das áreas e capacidades. (...) $5^{\circ}$ Arithmetica prática, compreendendo as quatro operações, frações decimais e ordinárias, systema métrico, proporções, regra de três, cálculos de juros. Problemas concretamente formulados.

No mesmo documento, conforme o Art.54.- O curso d'essas escolas durará obrigatoriamente seis anos, sendo dois para o curso elementar, dois para o curso médio e dois para o curso superior. Ou seja, o ensino primário durava seis anos e estava subdividido em três cursos com duração de dois anos cada.

Assim, no curso médio do ensino primário, de acordo com o documento supracitado, consta o ensino de $4^{\circ}$-Arithmetica prática até, regra de três simples, systema métrico, cálculos práticos e problemas concretos. Prática de systema métrico. 50- Geometria prática. 
Construção prática das figuras planas no quadro preto. Medição prática das áreas e capacidades.

Percebemos que no ensino de Geographia da escola primária, também está explícito o uso do sistema métrico na recomendação de ser ensinado o Estudo topographico da escola e do sítio escolar, passando progressivamente a localidade e depois ao município, indicados não só os accidentes physicos como a população, administração, producções, commercio e industria. Primeiros elementos de dezenho de mappas. Geographia physica, política e econômica do Estado. Noções geraes de geographia physica da terra.

E, no Curso Superior, havia o ensino de $3^{\circ}$ - Arithmetica prática e theorica até as raízes quebradas e cúbicas, excluídos os logarithmos. Noções práticas de escripturação mercantil e cálculos commerciaes. 40- Geometria, estudo de sólidos, representação graphica dos sólidos no quadro preto rudimentos práticos de trigonometria e agrimensura. $7^{\circ}$ (...) Desenho na pedra, de cartas geographicas geraes e especiaes do Brazil.

Ressaltamos ainda, nesse documento o Art.57- Nas escolas do sexo feminino, duas vezes por semana, nos dias designados para os exercícios physicos dos rapazes, a última hora será empregada no ensino de prendas e trabalhos femininos, dando-se preferência ao corte e confecção de peças de vestuário feminino e masculino e á costura.

Para que as alunas aprendessem a costurar elas seguramente teriam que aprender a utilizar os instrumentos de medidas como fita métrica ou trena para realizar as atividades de corte de tecidos, espaçamento no tecido para a costura, espaçamento ente os botões, etc.

A Instrução Secundária e Profissional era dada no Liceu Paraense com oferta de curso: 1-Letras e Ciências; pelo Instituto Paraense de Educandos Artífices, anexo ao Liceu, com dois cursos: $1^{\circ}$ - Comercio e o $2^{\circ}$-Agrimensura que requeria o aprendizado de instrumentos de medidas tais como teodolite, bussula, livello, além do ensino de cartografia e desenho linear topográfico. Deste modo, livros ilustrados (grande novidade) para mostrar os equipamentos métricos e efetivamente os equipamentos de medidas vão sendo introduzidos nas escolas posto que as recomendações pedagógicas requeriam aulas práticas.

No Instituto Lauro Sodré (anteriormente denominado de Instituto Paraense de Educandos Artífices), em 1901, a oferta era de curso agrícola e de curso industrial, sendo este último de acordo com a Monographia do Instituto no Art.18- são 7 cursos industriais: a) Carpinteiro, marceneiro e torneiro, b) Thypographo e impressor, c) Encadernador, d) Serralheiro e mechanico, e) Funileiro, f) Sapateiro, surrador, curtidor e corrieiro, g) Alfaiate.

Em todos os cursos ofertados pelo Instituto Lauro Sodré constava em seu Programa a cadeira Arithmetica cujo conteúdo era: Noções Geraes de Systema Metrico com exercícios práticos de suas principaes medidas. No segundo ano, na cadeira Arithmetica era realizada uma revisão do ensino precedente e o ensino do systema métrico decimal desenvolvido entre outros conteúdos sendo enfocado o lado prático das operações. No terceiro ano, a cadeira Arithmetica ensinava Systemas metrológicos, especialmente o decimal francez e a conversão de medidas. A cadeira Geometria ensinava avaliação de áreas; a cadeira Desenho ensinava escala de redução e estudo prático das projeções.

Particularmente alguns cursos precisavam mais da apropriação do conhecimento do sistema métrico decimal do que outros, como os cursos de sapateiro, alfaiate, marceneiro, embora todos os cursos para realizar suas produções dependiam desse conhecimento. Ressaltamos que o Instituto em 1903 entregou encomendas de fardamento para o Regimento Militar do Estado, encadernações e brochuras para o Palácio do Governo, gradios feitos sob medida para prédios públicos, se mostrando produtivo socialmente em atendimento as demandas forjadas pela efervescência da Belle Époque ocasionada pelo 
Primeiro Ciclo da Borracha demonstrando na prática a apropriação do conhecimento do sistema métrico francês.

Nessa época, as condições econômicas e sociais locais que favoreceram a esse processo ocorridas durante o Primeiro Ciclo da Borracha, tendo 30\% da população empregada na indústria extrativa do látex, no período que inicia em 1879, alcança o auge até 1912 e declina em 1920. A Província do Pará por ser a porta de entrada da cultura civilizada que vinha da Europa no momento de grande fomento econômico movido pela extração do látex, utilizado para fabricação de sernamby, caucho e borracha principal produto de exportação além de castanha, cacao, couros, madeiras, cachaça, guaraná, urucu, cumaru, óleo de copahyba, salsa, tapioca, peixes, grude entre outros produtos, durante o período denominado de Belle Époque, tendo como principal comprador a Inglaterra, além de outros países como Estados Unidos, Bélgica, França, Portugal.

O cenário paraense era de uma economia crescente, a segunda maior receita do Império, e a capital - Belém, com cem mil almas, possuía uma biblioteca pública, seis centros de leitura de grandes associações particulares, dez livrarias bem sortidas, jornais distribuídos diariamente pela manhã, bondes, telégrafo, iluminação pública, vapores no Porto, além da efervescência cultural com exposições artística e industrial, bandas de música e espetáculos de óperas no Theatro da Paz, alargamento de ruas, abastecimento de água.

O comércio no Pará era movimentado por indústrias pastoril, engenhos que fabricavam mel, açúcar e cachaça, havia fábricas de sabão, chocolate, cera, cerveja, licor, carruagens e arreios, além de lojas de sapateiro, alfaiate, funileiro, marceneiro e ferreiro. Na capital, Belém, havia uma lithographia, uma fábrica de cerâmica, uma de papel, outras fábricas de tecidos, de flores de pano, de redes, de doces e de louças de barro (CUNHA, 1887). E, neste cenário, o Sistema Métrico foi difundido pelas escolas do Pará.

O Sistema Métrico conhecido para aferição de pesos e medidas foi amplamente difundido no mundo, inclusive na Amazônia. Esta difusão não destruiu completamente os sistemas tradicionais de medidas preexistentes, assim, o sistema métrico dialogou com unidades do Sistema utilizado pela Inglaterra e Estados Unidos por causa do comércio e com os da cultura local.

O Sistema Métrico - importado da França nas escolas paraenses e, como pôde se ver que a cultura moderna com base no Iluminismo, reforçada pela Revolução Industrial e ensinada nas escolas via implantação de um processo civilizatório visando o progresso da região, foi difundida nos vários níveis de ensino - primário, secundário e profissional, desde o Brasil Império até o início da República, inaugurou aulas práticas de medidas com uso de réguas, trenas entre outros equipamentos, exercícios práticos no método intuitivo e livros, manuais e compêndios de matemática ilustrados, conforme a mentalidade da racionalidade científica que marcava a época, coincidindo com o período da Belle Époque amazônica. 


\section{Referências}

ALDER, Ken. The measure of the world. Washington: Smithsonian Instituction Libraries, 2003.

ARBOLEDA, Luis Carlos A. Acerca Del problema de La difusión científica em La periferia: El caso de La física newtoniana em La Nueva Granada (1740-1820). Quipu, vol.4, num. 1, PP. 7-30, enero-abril de 1987.

BARROS, J. B. A Escola Normal do Paraense e a introdução do ensino das Ciências Naturais no Pará. 78 f. Dissertação (Mestrado) - Universidade Federal do Pará, Instituto de Educação Matemática e Científica, Programa de Pós-Graduação em Educação em Ciências e Matemática, Belém, 2010.

CUNHA, Raymundo do Cyriaco Alves da. Pequena chronographya da Província do Pará. Belém: [s.M], 1887. ESTADO DO PARÁ. Monographia do Instituto Lauro Sodré. CENTUR, setor de obras raras.

LIMA, Luciano Mendonça. Derramando susto: os escravos e o Quebra-quilos. Dissertação de Mestrado, IFCH/UNICAMP, 2001.

LIMA, Viviane de Oliveira. Aprendendo com a História: o quebra-quilos na construção do imaginário nordestino. Anais do $3^{\circ}$ Seminário Nacional de História e Historiografia: aprender com a História. Ouro Preto: Edufop, 2009.

LIMA, Viviane de Oliveira. Revolta do Quebra-quilos: levantes populares contra o sistema métrico. Dissertação de Mestrado. Pós-grad. Em História/UFF, 2006.

ROZEMBERG, I. M. O Sistema Internacional de Unidades - SI. $3^{a}$ ed. ver e ampl. São Paulo: Instituto Mauá de Tecnologia, 2008. Disponível no site www.maua.br. Consultado em 02 de outubro de 2013.

PARATUR. www.paraturismo.pa.gov.br. Acessado em 19 de outubro de 2014.

REGULAMENTO GERAL DE INSTRUÇÃO PÙBLICA E ESPECIAL DO ENSINO PRIMARIO, 1891. CENTUR, setor de obras raras.

ROZEMBERG, Izrael Mordka. O Sistema Internacional de Unidades - SI. $3^{a}$ ed. ver e ampl. São Paulo: Instituto Mauá de Tecnologia, 2006. Disponível no site www.maua.br. Consultado em 02 de outubro de 2013.

SECRETO, Maria Verônica. (Des)medidas: a revolta do Quebra-Quilos (1874-1876), 2011.

SOUTO MAIOR, A. Quebra-Quilos: Lutas Sociais no Outono do Império- 2a. ed. São Paulo: Ed. Nacional,1978.

TRINDADE, Patrícia De Campos Corrêa. Instrumentos alternativos de pesos e medidas utilizados por ribeirinhos da região do baixo amazonas no estado do Pará. SBPC, 2009.

ZUIN, Elenice de Souza Lodron. Por uma nova aritmética: o sistema métrico decimal como um saber escolar em Portugal e no Brasil oitocentista. Tese de doutorado. PUC/SP, 2007. 